\title{
Optimization of a New Dissolution Test for Oxcarbazepine Capsules using Mixed-Level Factorial Design
}

\author{
Hudson C. Polonini, ${ }^{a}$ Marcone A. L. de Oliveira, ${ }^{b}$ Anderson O. Ferreira, ${ }^{c}$ \\ Nádia R. B. Raposo, ${ }^{a} L_{\text {Livia N. Grossi }}{ }^{c}$ and Marcos A. F. Brandão $o^{*, a}$ \\ ${ }^{a}$ Faculty of Pharmacy and ${ }^{b}$ Departament of Chemistry, Federal University of Juiz de Fora, \\ 36036-900 Juiz de Fora-MG, Brazil \\ ${ }^{c}$ Ortofarma - Controle de Qualidade, 36120-000 Matias Barbosa-MG, Brazil
}

\begin{abstract}
Neste trabalho foi desenvolvido e validado um teste de dissolução para cápsulas de oxcarbazepina. Para o estudo de triagem, foi utilizado um planejamento experimental de níveis mistos composto de fatores com dois e três níveis $\left(3^{2} \times 2\right)$, de modo a selecionar a velocidade de agitação, o meio de dissolução e o aparato. Esta estratégia é útil, pois reduz o tempo de desenvolvimento do método e também gera resultados mais exatos. A melhor porcentagem de dissolução foi obtida utilizando o aparato pá a $80 \mathrm{rpm}$ e com solução aquosa de laurilsulfato de sódio a $1 \% \mathrm{~m} / \mathrm{v}$ como meio de dissolução. A quantificação da massa dissolvida foi realizada por análise espectrofotométrica UV-Vis a $304 \mathrm{~nm}$. Os resultados do estudo da validação demonstraram que o método é preciso e linear no intervalo de $83-249 \mu \mathrm{g} \mathrm{mL} \mathrm{L}^{-1}$ de oxcarbazepina. Os resultados evidenciaram que o método apresenta utilidade e adequabilidade para o estudo da dissolução de cápsulas de oxcarbazepina, uma vez que não existe método oficial com este propósito.
\end{abstract}

In this work, a dissolution test for oxcarbazepine capsules was developed and validated. For the screening study, a mixed-level factorial design containing factors at three and two levels $\left(3^{2} \times 2\right)$ was used in order to select the stirring speed, the dissolution medium and the dissolution apparatus. This strategy is needful for reducing the time of method development and to provide less ambiguous data. The best in vitro percentage dissolution was obtained using apparatus paddle at $80 \mathrm{rpm}$ and sodium lauryl sulfate $1 \% \mathrm{~m} / \mathrm{v}$ aqueous solution as the dissolution medium. The quantification of the mass dissolved was obtained by UV-Vis spectrophotometric analysis at $304 \mathrm{~nm}$. The validation results demonstrate that the method was precise and linear over the range of $83-249 \mu \mathrm{g} \mathrm{mL}^{-1}$ of oxcarbazepine. Thus, the method is useful and adequate for oxcarbazepine capsules dissolution test, once there is no official monograph regarding it.

Keywords: oxcarbazepine, dissolution test, mixed-level factorial design

\section{Introduction}

Oxcarbazepine (OCBZ) (Figure 1) is a keto analog of carbamazepine ${ }^{1}$ indicated as monotherapy or adjunctive therapy for the treatment of partial seizures with or without secondarily generalized tonic-clonic seizures in adults and children aged over six years. ${ }^{2,3}$ The advantages of OCBZ on carbamazepine are: lower frequency and severity of adverse events (particularly endocrine), ${ }^{4-6}$ better tolerability, ${ }^{3,6}$ fewer drug interactions ${ }^{7}$ and almost complete absorption after oral ingestion. ${ }^{3}$

*e-mail: marcosbrand@uol.com.br<smiles>NC(=O)N1c2ccccc2CC(=O)c2ccccc21</smiles>

Figure 1. Chemical structure of oxcarbazepine (OCBZ, $\mathrm{C}_{15} \mathrm{H}_{12} \mathrm{~N}_{2} \mathrm{O}_{2}$ ).

Another point is that OCBZ is a low therapeutic index, high dosage and low potency drug. Its compounding and marketing, therefore, can only be made if the performance of the formulation is proved by conducting the dissolution test of the final product. ${ }^{8}$ 
Dissolution tests have become a highly valuable tool for quality analysis in the pharmaceutical industry in what concerns the performance of the oral solid dosage form/delivery system, ${ }^{9,10}$ because its results can be directly correlated to and reflect the bioavailability and bioequivalence of an active substance..$^{11}$ A regulatory approval is a requirement for the product to be marketed, and so the performance of oral solid dosage forms such as soft-gel capsules must be verified through an in vitro dissolution test. ${ }^{12,13}$

This in vitro dissolution test is so relevant for the pharmaceutical industries because it can predict the in vivo performance of a drug product, once the absorption of an oral drug is mainly dependent on the release of the active substance from its dosage form and also its dissolution and/or solubilization under physiological conditions. ${ }^{11}$ The capability of releasing the drug substance in aqueous media, making it available for gastrointestinal absorption, is indispensable for quality of the oral dosage forms..$^{10}$ Other important applications of the dissolution tests include the assessing of the batch-to-batch quality, the guidance for the development of new formulations and the assurance that changes in the original formulation do not affect the final product. ${ }^{11}$

After the dissolution testing, the amount of the substance dissolved should be determined by an adequate analytical procedure. This method has to be sufficiently sensitive, selective in presence of excipients, robust and rapid because the dissolution experiments generate a large number of samples. ${ }^{13}$

Many of the official pharmaceutical compendiums such as American, ${ }^{10}$ European, ${ }^{14}$ British, ${ }^{15}$ Japanese,${ }^{16}$ Brazilian ${ }^{17}$ pharmacopoeias have general chapters for dissolution harmonized among them, including its standards and policies. However, dissolution test of OCBZ capsule is not included in any of these pharmacopoeias, thus there is no official method description for this purpose. Within this context, a dissolution test using a simple UV-Vis spectrophotometric method to evaluate the dissolution performance of soft-gel capsules containing oxcarbazepine was developed, optimized and validated.

\section{Experimental}

\section{Reagents and materials}

The following analytical-grade reagents were used: sodium lauryl sulfate (SLS), hydrocholoric acid, tribasic sodium phosfate (all from Vetec, Rio de Janeiro, Brazil) and ethanol (Neon, São Paulo, Brazil). Oxcarbazepine (99.1\% purity) (Henrifarma, São Paulo, Brazil) was used as the reference material and as the raw material for the compounding of the capsules. Ultra-pure water (aquaMAX - Ultra 370 Series, Young Lin, Korea) was used for the dissolution medium and throughout analysis. The OCBZ capsules with $150 \mathrm{mg}$ were compounded using: soft-gel white/white n. 1 capsules (Catalent, Moorestown, NJ, USA) and the following preparation of excipients: pharmaceutical talc (Pharmanostra, Rio de Janeiro, RJ, Brazil), 3\%; colloidal silica (Deg, São Paulo, SP, Brazil), $1 \%$; SLS (Mapric, São Paulo, SP, Brazil), 1.5\%; corn starch (All Chemistry, São Paulo, SP, Brazil), q.s.p. (quantity sufficient for preparation) $100 \%$.

\section{Equipment}

OCBZ quantification was performed on a dual beam UV-Visible spectrophotometer system from Cary 50 Probe (Varian, Palo Alto, CA, USA) with 190-1100 nm absorption spectrum, $1.5 \mathrm{~nm}$ fixed spectral bandwidth, fiber optic reading probe and quartz regular cells of optical path equal to $1.0 \mathrm{~cm}$.

Dissolution tests were conducted in a dissolutor Mod 299 (Nova Ética, São Paulo, SP, Brazil). The equipment consists of $(i)$ six cylindrical glass vessels with hemispherical bottoms, nominal capacity of $1 \mathrm{~L}$, its sides are flanged at the top, and a fitted cover so that the evaporation of the dissolution media is retarded, (ii) a water bath that keeps the temperature inside the vessel at $37 \pm 0.5{ }^{\circ} \mathrm{C}$ during the test and (iii) a stainless steel drive shaft to which the dissolution apparatus can be attached and "positioned so that its axis is not more than $2 \mathrm{~mm}$ at any point from the vertical axis of the vessel and rotates smoothly and without significant wobble that could affect the results", ${ }^{10}$ (iv) a motor to rotate the shaft, and $(v)$ a speed-regulating device to select and maintain, within $4 \%$ of variation, the shaft rotation speed. The dissolution apparatus used were: (i) six stainless steel baskets with external diameter of $22.2 \pm 1.0 \mathrm{~mm}$, external height of $36.8 \pm 3.0 \mathrm{~mm}$ and mesh 40 screen with welded seam and (ii) six stainless steel paddles with height of $19.0 \pm 0.5 \mathrm{~mm}$, width of $74.5 \pm 0.5 \mathrm{~mm}$, and thickness of $4.0 \pm 1.0 \mathrm{~mm}$. The distance between the inside bottom of the vessel and the bottom of the apparatuses was maintained at $25 \pm 2 \mathrm{~mm}$. Illustrations of the design of the equipment can be found in the previously cited pharmacopoeias. ${ }^{10,14-17}$

Other equipments used were ultrasonic bath (Cristófoli, Campo Mourão, PR, Brazil), digital pHmeter W3B (Bel Engineering, Monza, Italy), electronic analytical balance AY 220 (Shimadzu, Kyoto, Japan), stainless steel sieve 60 mesh (Bronzinox, São Paulo, SP, Brazil) and porcelain mortar (Chiarotti, São Paulo, SP, Brazil). 


\section{Solutions}

All dissolution media used (hydrochloric acid $0.1 \mathrm{~mol} \mathrm{~L}^{-1}$, pH 6.8 phosphate buffer and SLS $1 \% \mathrm{~m} / \mathrm{m}$ aqueous solution) were degassed in ultrasonic bath for 30 min prior to use.

A pH 6.8 buffer potassium phosphate was prepared by adding $76 \mathrm{~g}$ of tribasic sodium phosphate in water to obtain $1000 \mathrm{~mL}$ of solution. An aliquot of $250 \mathrm{~mL}$ of this solution was mixed with $750 \mathrm{~mL}$ of hydrochloric acid $0.1 \mathrm{~mol} \mathrm{~L}^{-1}$. The $\mathrm{pH}$ value was checked with the $\mathrm{pHmeter}$ and if needed adjusted with hydrochloric acid $2 \mathrm{~mol} \mathrm{~L}^{-1}$ or sodium hydroxide $2 \mathrm{~mol} \mathrm{~L}^{-1}$, if necessary.

The standard solutions of OCBZ were prepared in a $1000 \mathrm{~mL}$ volumetric flask by dissolving an accurately weighed amount $(0.166 \mathrm{~g})$ of OCBZ standard in $10 \mathrm{~mL}$ of ethanol and diluting to volume with $1 \% \mathrm{~m} / \mathrm{v}$ SLS aqueous solution, hydrochloric acid or sodium phosphate buffer, depending on the dissolution medium used. It was used ultrasonic bath for solubilization of the OCBZ reference substance in the dissolution media. This solution was filtered through a $0.45 \mu \mathrm{m}$ porosity regenerated cellulose membrane (Macherey-Nagel, Duren, Germany) and used for the spectrophotometric analysis (final concentration ca. $\left.166 \mu \mathrm{g} \mathrm{mL} \mathrm{m}^{-1}\right)$.

Sample solutions were prepared in six replicates by putting one capsule in each vessel containing the dissolution medium $(900 \mathrm{~mL})$ at the temperature of $37 \pm 0.5{ }^{\circ} \mathrm{C}$ and using the adequate apparatus (final concentration ca. $166 \mu \mathrm{g} \mathrm{mL}^{-1}$ ). A sample aliquot of $10 \mathrm{~mL}$ was withdrawn from each vessel at the end of $60 \mathrm{~min}$ and filtered in a quantitative filter paper (Vetec, Rio de Janeiro, RJ, Brazil). This solution was assayed by spectrophotometry at $304 \mathrm{~nm}$, using the respective dissolution medium as blank. Masses of drug dissolved from the capsules were calculated by comparison with the standard solution measured by spectrophotometric analysis. ${ }^{18}$

\section{Factorial design with mixed levels}

In order to establish a method of analyzing dissolution of OCBZ, the following parameters were evaluated accordingly to criteria of The United States Pharmacopoeia (USP), ${ }^{10}$ The U. S. Food and Drug Administration (FDA), ${ }^{11}$ The International Conference on Harmonization (ICH) ${ }^{19}$ and the Brazilian Legislation: ${ }^{20}(i)$ dissolution medium at pH 6.8 phosphate buffer, $\mathrm{HCl} 0.1 \mathrm{~mol} \mathrm{~L}^{-1}$ and $1 \% \mathrm{~m} / \mathrm{v}$ SLS aqueous solution, (ii) 1 (basket) and 2 (paddle) concerning apparatus and (iii) stirring speed of 50, 75 and $100 \mathrm{rpm}$.

To evaluate the significance that each parameter/factor has on the dissolution of OCBZ and to determine the optimal conditions for inclusion of the method in routine laboratorial tests, a $3^{2} \times 2$ factorial design with mixed levels containing factors at three $(-1,0,+1$ for the factors stirring speed and dissolution medium) and two ( -1 and +1 for the factor dissolution apparatus) levels was randomly conducted in a total of 18 experiments with six replicates in each experimental level. ${ }^{21}$ The factors, levels and matrix of contrast coefficients are listed in Table 1.

Each experiment was conducted by adding one OCBZ capsule in a dissolution vessel $(n=6)$ containing $900 \mathrm{~mL}$ of dissolution medium stabilized at $37 \pm 0.5^{\circ} \mathrm{C}$ (variables kept constant). After $60 \mathrm{~min}$ of testing (usual time for immediate release solid pharmaceutical forms), ${ }^{21}$ aliquots of $10 \mathrm{~mL}$ were collected, filtered and measured directly in spectrophotometer at $304 \mathrm{~nm}$ using the dissolution medium as blank.

After the experiments, statistical analysis was conducted. ${ }^{22,23}$ From the results of each experiment, the coefficients for determining the statistical model prediction were calculated accordingly to equation 1 :

$b=\left(X^{t} X\right)^{-1} X^{t} y_{\mathrm{b}}$

where vector $b$ represents model parameter estimators, $X$ and $y$ are matrix and vector respectively, according to Table 1. To achieve the equation of the fitted model, it was calculated the standard errors of the coefficients using equation 2 :

$\varepsilon(b)=\sqrt{\left(X^{t} X\right)^{-1} \sigma^{2}}$

where $\varepsilon(b)$ is the matrix of standard errors of the elements of vector $b$ and $\sigma^{2}$ is the populational variance of the experiments, which can be estimated as $s^{2}$ using equation 3 :

$s_{\text {clustered }}^{2}=\frac{\sum_{i=1}^{18} v_{i} s_{i}^{2}}{\sum_{i=1}^{18} v_{i}}$

where $v_{i}$ and $s_{i}^{2}$ are the number of degree of freedom and the variance within each experimental level, respectively.

\section{Method validation}

The dissolution test was validated after establishing the optimal conditions. The validation of a dissolution test can be divided into two parts. The first one concerns equipment validation, once all equipment and glassware used has to be calibrated and qualified. ${ }^{24}$ Thus, the dissolutor was calibrated and so the glassware, by the Brazilian Calibration 
Table 1. Factors, levels, matrix of contrast coefficients and responses for $3^{2} \times 2$ mixed experimental design for dissolution of OCBZ capsules

\begin{tabular}{|c|c|c|c|c|c|c|c|c|c|c|c|c|c|c|c|c|c|c|c|}
\hline \multirow[b]{2}{*}{ Issues } & \multirow[b]{2}{*}{ Mean } & \multirow[b]{2}{*}{$X_{1}$} & \multirow[b]{2}{*}{$X_{2}$} & \multicolumn{5}{|c|}{ Contrast coefficients } & \multirow[b]{2}{*}{$X_{2} X_{3}$} & \multirow[b]{2}{*}{$X_{1} X_{2} X_{3}$} & \multicolumn{6}{|c|}{ Responses } & \multirow[b]{2}{*}{ Average } & \multirow[b]{2}{*}{ Variance } & \multirow[b]{2}{*}{$\mathrm{DF}$} \\
\hline & & & & $X_{3}$ & $X_{1}^{2}$ & $X_{2}^{2}$ & $X_{1} X_{2}$ & $X_{1} X_{3}$ & & & & & dissolv & ed $(n=$ & & & & & \\
\hline 1 & 1 & -1 & -1 & -1 & 1 & 1 & 1 & 1 & 1 & -1 & 50.46 & 51.02 & 51.57 & 49.16 & 51.14 & 49.97 & 50.55 & 0.78 & 5 \\
\hline 2 & 1 & 0 & -1 & -1 & 0 & 1 & 0 & 0 & 1 & 0 & 62.02 & 64.57 & 60.78 & 61.15 & 63.57 & 60.90 & 62.17 & 2.46 & 5 \\
\hline 3 & 1 & 1 & -1 & -1 & 1 & 1 & -1 & -1 & 1 & 1 & 63.32 & 65.87 & 65.43 & 64.25 & 67.17 & 67.29 & 65.56 & 2.49 & 5 \\
\hline 4 & 1 & -1 & 0 & -1 & 1 & 0 & 0 & 1 & 0 & 0 & 49.39 & 49.58 & 51.31 & 48.71 & 50.20 & 50.07 & 49.88 & 0.77 & 5 \\
\hline 5 & 1 & 0 & 0 & -1 & 0 & 0 & 0 & 0 & 0 & 0 & 58.89 & 57.90 & 57.52 & 56.84 & 59.14 & 59.01 & 58.22 & 0.88 & 5 \\
\hline 6 & 1 & 1 & 0 & -1 & 1 & 0 & 0 & -1 & 0 & 0 & 61.21 & 61.15 & 62.14 & 63.63 & 60.96 & 60.65 & 61.62 & 1.22 & 5 \\
\hline 7 & 1 & -1 & 1 & -1 & 1 & 1 & -1 & 1 & -1 & 1 & 85.96 & 85.83 & 84.91 & 82.43 & 85.09 & 83.17 & 84.56 & 2.08 & 5 \\
\hline 8 & 1 & 0 & 1 & -1 & 0 & 1 & 0 & 0 & -1 & 0 & 87.97 & 88.34 & 91.18 & 92.05 & 87.47 & 84.38 & 88.57 & 7.62 & 5 \\
\hline 9 & 1 & 1 & 1 & -1 & 1 & 1 & 1 & -1 & -1 & -1 & 87.69 & 86.51 & 85.33 & 88.93 & 89.11 & 86.63 & 87.37 & 2.21 & 5 \\
\hline 10 & 1 & -1 & -1 & 1 & 1 & 1 & 1 & -1 & -1 & 1 & 52.62 & 51.63 & 53.67 & 52.68 & 52.19 & 54.10 & 52.81 & 0.85 & 5 \\
\hline 11 & 1 & 0 & -1 & 1 & 0 & 1 & 0 & 0 & -1 & 0 & 66.09 & 64.93 & 65.00 & 64.39 & 66.29 & 66.77 & 65.58 & 0.87 & 5 \\
\hline 12 & 1 & 1 & -1 & 1 & 1 & 1 & -1 & 1 & -1 & -1 & 69.97 & 66.92 & 67.86 & 65.19 & 66.29 & 66.77 & 67.17 & 2.64 & 5 \\
\hline 13 & 1 & -1 & 0 & 1 & 1 & 0 & 0 & -1 & 0 & 0 & 50.07 & 51.06 & 50.01 & 50.50 & 49.57 & 50.44 & 50.28 & 0.26 & 5 \\
\hline 14 & 1 & 0 & 0 & 1 & 0 & 0 & 0 & 0 & 0 & 0 & 60.30 & 59.24 & 59.31 & 58.75 & 60.49 & 60.92 & 59.83 & 0.73 & 5 \\
\hline 15 & 1 & 1 & 0 & 1 & 1 & 0 & 0 & 1 & 0 & 0 & 62.33 & 61.78 & 62.21 & 63.70 & 62.71 & 64.26 & 62.83 & 0.91 & 5 \\
\hline 16 & 1 & -1 & 1 & 1 & 1 & 1 & -1 & -1 & 1 & -1 & 82.90 & 83.65 & 79.37 & 84.14 & 78.68 & 80.98 & 81.62 & 5.25 & 5 \\
\hline 17 & 1 & 0 & 1 & 1 & 0 & 1 & 0 & 0 & 1 & 0 & 94.16 & 93.10 & 92.91 & 95.59 & 91.92 & 97.40 & 94.18 & 4.05 & 5 \\
\hline 18 & 1 & 1 & 1 & 1 & 1 & 1 & 1 & 1 & 1 & 1 & 89.95 & 90.57 & 90.20 & 90.07 & 89.70 & 90.44 & 90.15 & 0.10 & 5 \\
\hline
\end{tabular}

$X_{1}$ : stirring speed (rpm): (-1):50; (0):75; (+1):100; $X_{2}$ : dissolution medium: (-1): phosphate buffer pH 6.8; (0): $\mathrm{HCl} 0.1 \mathrm{~mol} \mathrm{L-1} ;(+1): \mathrm{SLS} 1 \% \mathrm{~m} / \mathrm{v} ; X_{3}$ : apparatus: $(-1)$ : basket; $(+1)$ : paddle; $\mathrm{DF}=$ degrees of freedom; \% dissolved $=\frac{\mathrm{C}_{\text {standard }}}{\mathrm{A}_{\text {standard }}} \times \frac{\mathrm{A}_{\text {sample }}}{\mathrm{C}_{\text {sample }}} \times \mathrm{P}$, where $\mathrm{C}$ is the concentration, $\mathrm{A}$ is the absorbance
and $\mathrm{P}$ is the purity/potency of the standard.

Network. The second part regards the test validation itself. In this case, the dissolution test is categorized by USP ${ }^{10}$ and Brazilian legislation ${ }^{25}$ as "category III - performance test", being the parameter precision required. It were also evaluated the parameters linearity and limits of detection and quantification. ${ }^{26}$

\section{Linearity}

The test was performed from three analytical curves, plotted from the concentrations of 50-150\% of the OCBZ work concentration (real concentrations: 83, 124, 166, 208 and $249 \mu \mathrm{g} \mathrm{mL}^{-1}$ ), to assess a linear relationship between analyte concentration and absorbance. For this purpose, data from each concentration level were statistically evaluated using analysis of variance (ANOVA) and the value of the correlation coefficient of the analytical curve.

\section{Limits of Detection and Quantification}

The limit of detection (LOD) and limit of quantification (LOQ) of the proposed method were determined from three standard analytical curves and they were calculated using equations 4 and 5:

$$
\begin{aligned}
& L O D=S \frac{3}{a} \\
& L O Q=S \frac{10}{a}
\end{aligned}
$$

where $S$ is the standard deviation of the intercept with the $\mathrm{y}$ axis of the three analytical curves and $a$ is their slope.

\section{Precision}

The precision was assessed by the coefficient of variation, determined for the repeatability and the intermediate precision. The repeatability (intra-assay precision) was assessed by analyzing seven replicates at the concentration of $166.6 \mu \mathrm{g} \mathrm{mL}^{-1}$ of OCBZ $(100 \%)$. The intermediate precision consisted of the same test, but performed for two consecutive days with two different analysts. A coefficient of variation $<5 \%$ was considered appropriate. ${ }^{25}$

\section{Software}

All statistical analysis was performed in Microsoft Office ${ }^{\circledR}$ Excel 2007 software, which is easy to use and therefore can be widely applied in teaching the topics elaborated upon here.

\section{Results and Discussion}

Factorial design is a very useful tool to obtain deeper information about the relationships among the studied variables and to establish the optimum experimental conditions. Its application to dissolution studies is needful for reducing the time of method development and to provide 
less ambiguous data. ${ }^{27}$ The application of experimental design for optimizing the dissolution test is a valuable tool for reducing the amount of work needed for formulation and test development. In fact, the factorial design makes possible the reduction of the number of single experiments and the improvement of the method reliability. ${ }^{28}$

In the present study, each experiment was conducted in a number of 6 replicates because of the design of the equipment, which contains 6 dissolutions vessels and because the pharmacopoeic acceptance criterion states that is needed to have 6 units being tested in order to achieve an adequate overview of the dosage form dissolution quality. The pharmacopeias have harmonized general chapters for dissolution test, and they recommend that the first 6 units must give results fallen within the specification " $Q+5 \%$ ", being $Q$ the amount of dissolved active ingredient specified in the individual monograph, expressed as a percentage of the labeled content of the dosage unit. This value is generally $75-80 \% .{ }^{29}$ However, it is acceptable that the dosage form does not meet this first requirement. In this case, another test must be conducted therefore with additional 6 units (criterion: the average of the 12 units, the first 6 and the additional ones, must be equal to or greater than $Q$, and no unit is less than " $Q-15 \%$ "). Once the results do not show adequate values, the test is repeated with more 12 capsules (specification: the average of the all 24 units must be equal to or greater than $Q$, not more than 2 units are less than " $Q-15 \%$ " and no unit is less than " $Q-25 \%$ "). . $^{10,14,16,17}$

When there is no official monograph for a given medicine, the method has to be developed and validated, and the referred $Q$ value can be selected by the authors, provided it has a plausible justification. In this case, it was chosen to work with $Q=80 \%$, because of its widespread use by the pharmacists. The other test parameters had also to be selected. According to the Brazilian legislation, ${ }^{20}$ one has to investigate three different dissolution media (all within the physiological $\mathrm{pH}$ 1.2-6.8). Oxcarbazepine is wellcharacterized as a water-insoluble drug, ${ }^{10}$ thus it is required to use dissolution media dissimilar from the normally employed in this type of test. In this sense, the utilization of surfactants such as the SLS is largely widespread, once it mimics, up to some extent, the human body physiologically conditions, such as the presence of natural surfactants (bile salts and lecithin, for instance) in the gastrointestinal tract. Surfactants as the SLS are wetting, micellar solubilizing agents, so they have the capacity of enhancing the solubility of such drugs. This probably happens via the reduction of the interfacial tension and/or their association with the excipients and the active ingredient itself. Nevertheless, it is recommended that these substances are used only in small concentrations, so that the in vitro/in vivo results are better correlated ${ }^{29}$ so that is why it was chosen to work with the concentration of $1 \% \mathrm{~m} / \mathrm{v}$. The other media was chosen to verify whether the substance is better solubilized in acidic or neutral $\mathrm{pH}$.

In addition to the dissolution medium, it were also measured the influence of two stirring apparatus (basket and paddle, the most commonly used) and three different stirring speeds $(50,75$ and $100 \mathrm{rpm}$, also the most commonly used in the in the pharmaceutical field). The dissolution experiment was therefore conducted using a $3^{2} \times 2$ mixed-level factorial design, in a total of 18 experiments, whose parameters are described in Table 1, as well as the contrast coefficients for the interaction effects of the factors and the results of each experiment.

In Table 1, can be seen that keeping $X_{3}$ (apparatus) fixed at level-1, it appears that the increased level of $X_{1}$ (stirring speed), when $X_{2}$ (dissolution medium) is kept constant, leads to higher response, except when $X_{2}$ is at level +1 . In this case, the highest response occurs when $X_{1}$ is at level 0 . The same analysis is true when one considers the level $X_{3}$ fixed at +1 , which suggests that the answer related to $X_{1}$ is likely to forecast, with the two other factors held constant. Similarly, when $X_{3}$ remains fixed at level -1 , the response as a function of $X_{2}$, with $X_{1}$ fixed, also follows predictable behavior, but differently from what happens in the previous situation. With $X_{2}$, the lower response is observed at level 0 and the highest at level +1 . When $X_{1}$ and $X_{2}$ are set constant to investigate the effect of $X_{3}$ on the response, it is observed that changing the level -1 to +1 always leads to an increased response. Thus, from this initial screening, it appears that higher responses are observed when the agitation speed is at levels $+1\left(100 \mathrm{rpm}\right.$, when $X_{2}$ is at -1 and 0$)$ and 0 (75 rpm, when $X_{2}$ is +1$)$, the dissolution medium at level $+1(1 \% \mathrm{~m} / \mathrm{v}$ SLS) and the apparatus at level +1 (paddle). However, it was performed a study involving factorial surface response for the experiments in order to achieve and verify the optimal conditions for the dissolution test.

Calculating the coefficients of the statistical model using the equations 1, 2 and 3 (Tables S1 and S2), it was obtained $\hat{y}=60.03( \pm 0.30)+5.41 x_{1}( \pm 0.17)+13.55 x_{2}$ $( \pm 0.17)+0.88 x_{3}( \pm 0.14)-4.38 x_{1}^{2}( \pm 0.29)+17.08 x_{2}^{2}$ $( \pm 0.29)-2.25 x_{1} x_{2}( \pm 0.20)+0.49 x_{1} x_{3}( \pm 0.17)-0.15 x_{2} x_{3}$ $( \pm 0.17)+0.79 x_{1} x_{2} x_{3}( \pm 0.20)$. The significance evaluation for each error using $t$ value (ca. 2.0) with 90 degrees of freedom was performed and only coefficient $x_{2} x_{3}$ was considered no significant for $95 \%$ confidence, because contain zero within the interval. In order to verify the model lack of fit, it was performed the analysis of variance according to Table 2 . The percentage of variation explained by regression and maximum percentage of variation explained were equal to 98.70 and $99.23 \%$, respectively. 
Table 2. Analysis of variance for fitting the model of prediction for the screening study

\begin{tabular}{lccc}
\hline Source & $\begin{array}{c}\text { Sum of } \\
\text { square (SS) }\end{array}$ & $\begin{array}{c}\text { Number of } \\
\text { degrees of freedom }\end{array}$ & $\begin{array}{c}\text { Mean of } \\
\text { square (MS) }\end{array}$ \\
\hline Model & 23175.86 & 9 & 2675.09 \\
Residual & 305.64 & 98 & 3.12 \\
Lack of fit & 124.77 & 8 & 15.57 \\
Pure error & 180.87 & 90 & 2.01 \\
Total & 23481.50 & 107 & \\
\hline
\end{tabular}

$\%$ variation explained $=98.70 ; \%$ maximum of variation explained $=$ 99.23 .

The regression significance test returned the value of $\mathrm{F}_{\text {calculated }}\left(\mathrm{MS}_{\text {model }} / \mathrm{MS}_{\text {residual }}\right)=825.68$, higher than $\mathrm{F}_{\text {critical0.05,vl=9,v2 }=98} \quad c a .2 .00$, which indicates a significant regression within $95 \%$ confidence interval. On the other hand, the lack of fit test returned $\mathrm{F}_{\text {calculated }}\left(\mathrm{MS}_{\text {lack of fit }} / \mathrm{MS}_{\text {pure error }}\right)=7.76$, higher than $\mathrm{F}_{\text {criticala.05, vl }=8, v 2=90} c a$. 2.06, which indicates lack of fit within $95 \%$ confidence interval. However, taking into account that the lack of fit presented by the model is relatively small and probably represents a minor region in the surface; that the percentage of variation explained by regression and maximum percentage of variation explained are close; and the model residue presented normal behavior through Kolmogorov normality test for $95 \%$ confidence ( $p$-value > 0.05 ) The response surface was built from the experiments (Figure 2 and S1) and indicated as higher response the region (\% dissolution) between 40-80 rpm (Table S3), using $1 \% \mathrm{~m} / \mathrm{v}$ SLS. This response surface was achieved fixing variable apparatus in "paddle" (level +1$)$. This was made because both apparatuses lead to similar results in the dissolution experiments, thus the decision was made taking into account that the paddle has a more widespread utilization

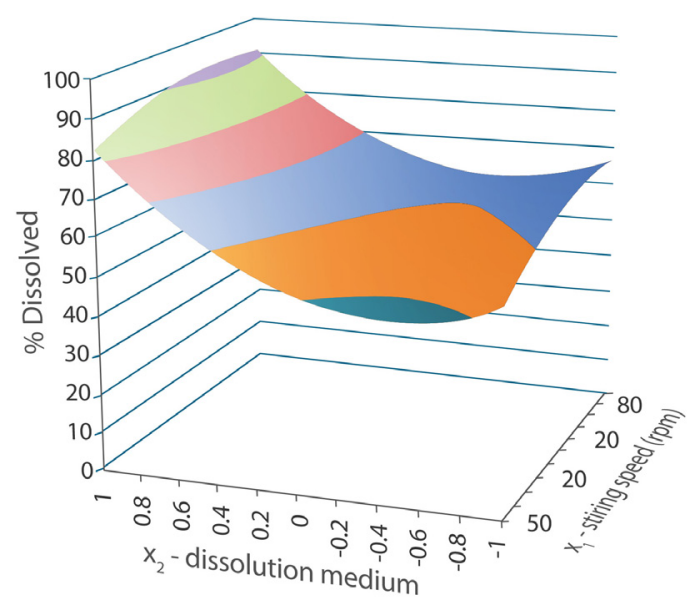

Figure 2. Response surface for the $3^{2} \times 2$ mixed factorial design. $X_{1}=$ stirring speed (rpm); $X_{2}=$ dissolution medium. than the basket. With respect to the stirring speed, once 40, 60 and $80 \mathrm{rpm}$ led to very similar theoretical dissolution result, it was chosen to work with $80 \mathrm{rpm}$.

The optimal conditions (stirring speed set at $80 \mathrm{rpm}$ ) would theoretically lead to a percentage of dissolution of about $92.15 \%$. Since these conditions provided by the response surface methodology had not been tested previously, the experiment was run again using the provided levels by the methodology, with six replicates. The average percentage dissolved for these conditions was $95.45 \%$, higher than that found in the initial screening experiments and even higher than the predicted value obtained with the response surface methodology (in the whole optimized region for stirring speed, i.e. 40-80 rpm). Though it has presented a lower value compared to the real one, the model was able to predict which one were the best levels for each parameter of the test. So, it can be inferred that this methodology is highly relevant to the objectives proposed here. Therefore, the established conditions to validate the dissolution test were: $X_{1}=80 \mathrm{rpm}, X_{2}=\operatorname{SLS} 1 \% \mathrm{~m} / \mathrm{v}$ aqueous solution and $X_{3}=$ paddle.

\section{Method validation}

The linearity of the method used was evaluated on a calibration curve of the absorbance $v s$. the analyte concentration $\left(\mu \mathrm{g} \mathrm{mL}^{-1}\right)$. The calibration curves, performed in genuine triplicate, returned the model $y( \pm 0.0035)=0.0096( \pm 0.000015) x+0.0029( \pm 0.0027)$, with $\mathrm{r}^{2}=0.99996$. To validate this model, it was performed the analysis of variance described in Table 3. The test of significance of regression returned the value of $\mathrm{F}_{\text {calculated }}\left(\mathrm{MS}_{\text {model }} / \mathrm{MS}_{\text {residual }}\right)=391107.8$, greater than $\mathrm{F}_{\text {criticallo. } 01, v l=1, v 2=13}=4.67$, which confirms the existence of a significant linear relationship between the two variables, with $95 \%$ confidence. The test of lack of fit value returned $\mathrm{F}_{\text {calculated }}\left(\mathrm{MS}_{\text {lack of fit }} / \mathrm{MS}_{\text {pure error }}\right)=5.06$, smaller than

Table 3. Analysis of variance for fitting the model of prediction for the validation study

\begin{tabular}{lccc}
\hline Source & $\begin{array}{c}\text { Sum of } \\
\text { square (SS) }\end{array}$ & $\begin{array}{c}\text { Number of degrees } \\
\text { of freedom }\end{array}$ & $\begin{array}{c}\text { Mean of } \\
\text { square (MS) }\end{array}$ \\
\hline Model & 4.80 & 1 & 4.80 \\
Residual & $1.59 \times 10^{-4}$ & 13 & $1.22 \times 10^{-5}$ \\
Lack of fit & $9.63 \times 10^{-5}$ & 3 & $3.20 \times 10^{-5}$ \\
Pure error & $6.33 \times 10^{-5}$ & 10 & $6.33 \times 10^{-6}$ \\
Total & 4.80 & 14 & \\
\hline
\end{tabular}

$\%$ variation explained by regression $=99.99 ; \%$ maximum of variation explained $=99.99$. 
$\mathrm{F}_{\text {critical } 0.01, v 1=3, v 2=10}=6.55$, which indicates no lack of fit, with 99\% confidence.

The lowest concentration of an analyte in a sample that it is possible to detect, but not to quantify is considered the LOD. The LOQ has the same definition, but determines the lowest concentration of an analyte in a sample that can be determined/quantified with acceptable precision and accuracy. ${ }^{30,31}$ By calculations using equations 4 and 5, the LOD was determined as $0.84 \mu \mathrm{g} \mathrm{mL}^{-1}$ and the LOQ as $2.81 \mu \mathrm{g} \mathrm{mL}{ }^{-1}$, which demonstrates the method is sensitive enough to the proposed objective. The calculation of the LOQ and LOD is useful, in the dissolution case, because some capsules do not dissolve adequate amounts of the active ingredient due to problems in the formulation, caused mainly by the choice of the excipients. Thus the method has to be sensitive enough to be applied to a wide range of possibilities found in the pharmaceutical industries.

The precision of the method (repeatability and intermediate precision) is a measure of the degree of repeatability of an analytical method under normal operation. Its evaluation is very important in order to assess the reliability of the dissolution test data. ${ }^{25}$ In the case of dissolution test (as previously informed, a "category III performance test"), it is needed to verify the repeatability through a minimum of 6 determinations/experiments with the work concentration of the substance $(100 \%$, i.e. $\left.166 \mu \mathrm{g} \mathrm{mL} \mathrm{m}^{-1}\right)$. A coefficient of variation (CV) of less than $5 \%$ is considered appropriate. ${ }^{30,31}$ It was achieved repeatability values of $3.0 \%(n=7)$.

For the intermediate precision, it is recommended to perform the test in two different days with two different analysts, aiming to assess the inherent variability of the method. For this test, it is also considered as satisfactory a $\mathrm{CV}$ value lower than $5 \%$. The intermediate precision coefficient of variation achieved was $4.2 \%(n=14)$.

Other parameters such as accuracy and specificity were not performed because the legislation ${ }^{25}$ does not consider them as mandatory for dissolution tests. Since the emphasis of this study was not the validation, but the application of the mixed-level factorial design in dissolution tests development, the authors chose not to include these two figures of merit.

To sum up, this work opens a new perspective in the dissolution test development methodology, since it is the first time that the mixed-level factorial design was used for this purpose. As it was successfully applied for the OCBZ capsules case, it can be inferred that it can be also applied for virtually any drug that needs a dissolution study. Using the fundamentals here presented, one can develop it for a variety of pharmaceutical dosage forms, composed by several different active ingredients.

\section{Conclusions}

On balance, this work provided a simple and validated procedure for dissolution test of oxcarbazepine capsules by UV-Vis spectrophotometric analysis. The $3^{2} \times 2$ mixed factorial design carried out an optimized dissolution test for: apparatus 2 (paddle) at $80 \mathrm{rpm}$ and sodium lauryl sulfate $1 \% \mathrm{~m} / \mathrm{v}$ aqueous solution, as the dissolution medium. Data analysis demonstrates the method was validated with respect to linearity, precision and limits of detection and quantification. The method is useful and adequate for oxcarbazepine capsules dissolution test, once there is no official monograph regarding it. Moreover, the mixed-level factorial design presented can be applied for the dissolution method development of virtually any drug substance candidate, or even the already marketed ones.

\section{Supplementary Information}

Supplementary information is available free of charge at http://jbcs.org.br as a PDF file.

\section{Acknowledgement}

The authors would like to thank Conselho Nacional de Desenvolvimento Científico e Tecnológico (CNPq - 300593/2008-2), Fundação de Amparo à Pesquisa do Estado de Minas Gerais (FAPEMIG, CEX PPM 00326/09), Singularis Farmácia de Manipulação and Michele Campos, for her invaluable help.

\section{References}

1. Buggy, Y.; Layton, D.; Fogg, C.; Shakir, S. A. W.; Epilepsia 2010, 51, 818 .

2. Novartis Pharmaceuticals; Trileptal (R), Summary of Product Characteristics, 2009.

3. Shorvon, S.; Seizure 2000, 9, 75.

4. Tecoma, E. S.; Epilepsia 1999, 40, S37.

5. Bill, P. A.; Vigonius, U.; Pohlmann, A.; Guerreiro, C. A.; Kochen, S.; Saffer, D.; Moore, A.; Epilepsy Res. 1997, 27, 195.

6. Dam, M.; Ekberg, R.; Løyning, Y.; Waltimo, O.; Jakobsen, K.; Epilepsy Res. 1989, 3, 70.

7. Schmidt, D.; Elger, C. E.; Epilepsy Behav. 2004, 5, 627.

8. Agência Nacional de Vigilância Sanitária (ANVISA); Critérios adicionais de Boas Práticas de Manipulação de Medicamentos em Farmácias, Resolução RDC n. 354, Brasil, 2003.

9. Cohen, J. L.; Hubert, B. B.; Leeson, L. J.; Rhodes, C. T.; Robinson, J. R.; Roseman, T. J.; Shefter, E.; Pharm. Res. 1990, 7, 983. 
10. The United States Pharmacopeial Convention, The United States Pharmacopeia, USP 33, Rockville, 2010.

11. The United States Food and Drug Administration (USFDA), Guidance for Industry: Dissolution Testing of Immediate Release Solid Oral Dosage Forms, Food and Drug Administration, Rockville, 1997.

12. Frost, S. M. A.; Dissolution Technol. 2004, 11, 19.

13. Davydova, N.; Stippler, E.; Jin, P.; Giancaspro, G.; J. Pharm. Biomed. 2010, 53, 295.

14. European Pharmacopoeia, $6^{\text {th }}$ ed., Council of Europe: Strasbourg, 2008.

15. British Pharmacopoeia, Her Majesty's Stationery Office: London, 2010.

16. The Pharmaceutical Society of Japan, Japanese Pharmacopeia, $15^{\text {th }}$ ed., Tokyo, 2006.

17. Farmacopéia Brasileira, 4a. ed., Atheneu Editora: São Paulo, Brasil, 2005.

18. Corrigan, O. I.; Stanley, T.; J. Pharm. Pharmacol. 1982, 34, 621.

19. ICH, International Conference on Harmonization of Technical Requirements for Registration of Pharmaceuticals for Human Use, Q2B(R1), Guideline on Validation of Analytical Procedure: Text and Methodology, Geneve, 2005.

20. Agência Nacional de Vigilância Sanitária (ANVISA); Estudos de Equivalência Farmacêutica e de Perfil de Dissolução Comparativo, Resolução RDC n. 31, Brasil, 2010.

21. Agência Nacional de Vigilância Sanitária (ANVISA); Guia para Ensaios de Dissolução para Formas Farmacêuticas Sólidas Orais de Liberação Imediata (FFSOLI), Resolução RDC n. 483, Brasil, 2010
22. Montgomery, D. C.; Design and Analysis of Experiments, $6^{\text {th }}$ ed., Wiley: New York, 2004.

23. Barros Neto, B.; Scarminio, I. S.; Bruns, R. E.; Como fazer Experimentos: Pesquisa e Desenvolvimento na Ciência e na Indústria, 4a. ed., Bookman: Porto Alegre, Brasil, 2010.

24. Frick, A.; Moller, H.; Wirbitzki, E.; Eur. J. Pharm. Biopharm. 1998, 46, 305.

25. Agência Nacional de Vigilância Sanitária (ANVISA); Validação de Métodos Bioanalíticos, Resolução RE n. 899, Brasil, 2003.

26. Ansari, M.; Kazemipour, M.; Talebnia, J.; Dissolution Technol. 2004, 11, 16 .

27. Mohd, A. A.; Dean, J. R.; Tomlinson, W. R.; Analyst 1992, 117, 1743.

28. Furlanetto, S.; Maestrelli, F.; Orlandini, S.; Pinzauti, S.; Mura, P.; J. Pharm. Biomed. Anal. 2003, 24, 159.

29. Shah, V. P.; Konecny, J. J.; Everett, R. L.; McCullough, B.; Noorizadeh, A. C.; Skelly, J. P.; Pharm. Res. 1989, 6, 612.

30. Shabir, G. A.; J. Chromatogr. A 2003, 987, 57.

31. Instituto Nacional de Metrologia (INMETRO); Normalização e Qualidade Industrial, Orientações sobre Validação de Métodos de Ensaios Químicos, Documento DOQ-CGCRE-008, Brasil, 2003. 


\title{
Optimization of a New Dissolution Test for Oxcarbazepine Capsules using Mixed-Level Factorial Design
}

\author{
Hudson C. Polonini, ${ }^{a}$ Marcone A. L. de Oliveira, ${ }^{b}$ Anderson O. Ferreira, ${ }^{c}$ \\ Nádia R. B. Raposo, ${ }^{a}$ Lívia N. Grossi $^{c}$ and Marcos A. F. Brandão $o^{*, a}$ \\ ${ }^{a}$ Faculty of Pharmacy and ${ }^{b}$ Departament of Chemistry, Federal University of Juiz de Fora, \\ 36036-900 Juiz de Fora-MG, Brazil \\ ${ }^{\text {c} O r t o f a r m a-C o n t r o l e ~ d e ~ Q u a l i d a d e, ~ 36120-000 ~ M a t i a s ~ B a r b o s a-M G, ~ B r a z i l ~}$
}

Table S1. "b" Coefficient calculation

\begin{tabular}{lccc}
\hline & Coefficients & \multicolumn{2}{c}{ Significant intervals } \\
\hline Mean & 60.03591 & 59.42733 & 60.64448999 \\
$X_{1}$ & 5.415861 & 5.082528 & 5.749194615 \\
$X_{2}$ & 13.55133 & 13.218 & 13.8846618 \\
$X_{3}$ & 0.886864 & 0.614698 & 1.1590292 \\
$X_{12}$ & -4.3891 & -4.96645 & -3.81174705 \\
$X_{22}$ & 17.08021 & 16.50286 & 17.65755911 \\
$X_{1} X_{2}$ & -2.25243 & -2.66068 & -1.84418205 \\
$X_{1} X_{3}$ & 0.490914 & 0.157581 & 0.824247368 \\
$X_{2} X_{3}$ & -0.15214 & -0.48547 & 0.181192138 \\
$X_{1} X_{2} X_{3}$ & 0.798203 & 0.389955 & 1.206451261 \\
\hline
\end{tabular}

The coefficients were calculated using: $\left(X^{t} X\right)^{-1} X^{t} y$; significant intervals were calculated using: $b_{i} \pm$ error $\times t_{0.05, v=90}$.

Table S2. Standard error calculation of the "b" coefficients

\begin{tabular}{c|c|c|c|c|ccccc}
\hline 0.30429 & 0 & 0 & 0 & 0 & 0 & 0 & 0 & 0 & 0 \\
0 & 0.166667 & 0 & 0 & 0 & 0 & 0 & 0 & 0 & 0 \\
0 & 0 & 0.166667 & 0 & 0 & 0 & 0 & 0 & 0 & 0 \\
0 & 0 & 0 & 0.136083 & 0 & 0 & 0 & 0 & 0 & 0 \\
0 & 0 & 0 & 0 & 0.288675 & 0 & 0 & 0 & 0 & 0 \\
0 & 0 & 0 & 0 & 0 & 0.288675 & 0 & 0 & 0 & 0 \\
0 & 0 & 0 & 0 & 0 & 0 & 0.204124 & 0 & 0 & 0 \\
0 & 0 & 0 & 0 & 0 & 0 & 0 & 0.166667 & 0 & 0 \\
0 & 0 & 0 & 0 & 0 & 0 & 0 & 0 & 0.166667 & 0 \\
0 & 0 & 0 & 0 & 0 & 0 & 0 & 0 & 0 \\
\hline
\end{tabular}

The standard errors were calculated as the square root of $\left(X^{t} X\right)^{-1} \times \mathrm{s}_{\text {clustered }}^{2}$.

*e-mail: marcosbrand@uol.com.br 
Table S3. Plotting of the response surface. The levels were substituted in the statistical model in order to find the region of best response

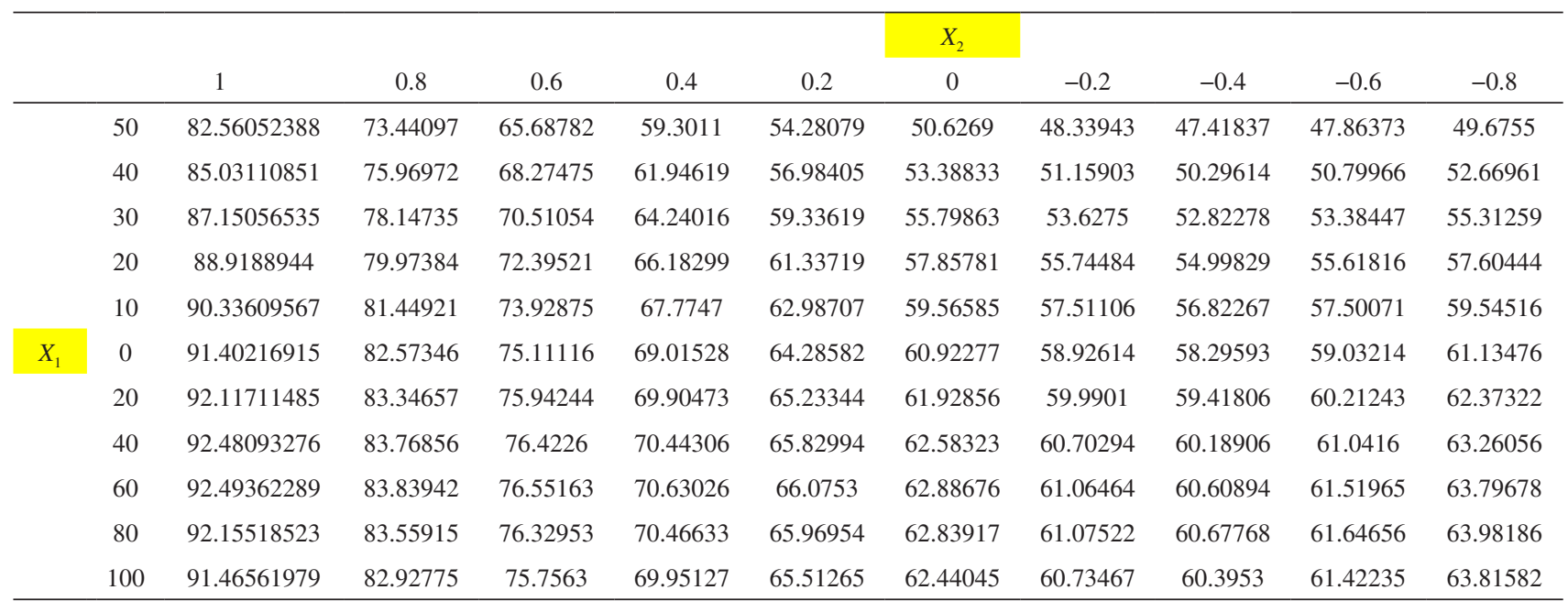

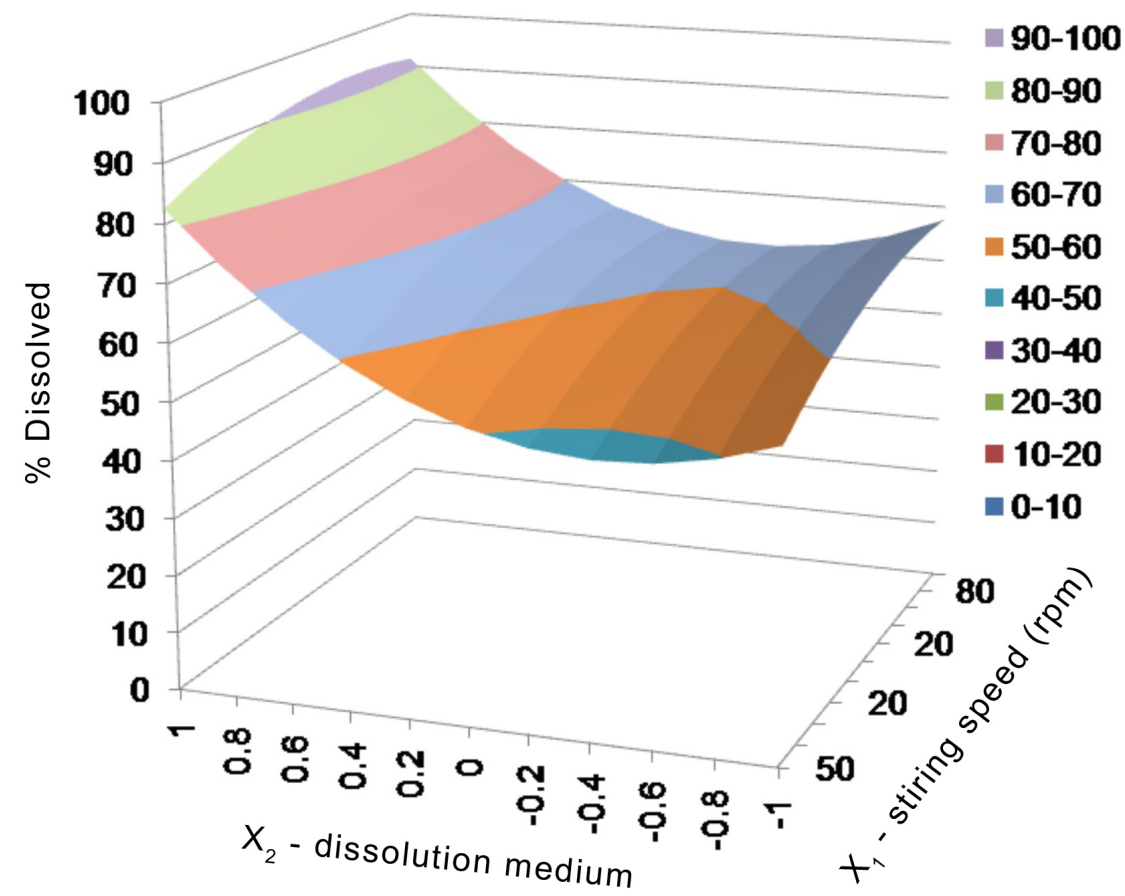

Figure S1. Response surface for the $3^{2} \times 2$ mixed factorial design. $X_{1}=$ stirring speed (rpm); $X_{2}=$ dissolution medium. 